\title{
Using qualitative interviews with nihr crn research midwives to refine trial recruitment methods
}

\author{
Katharine Foster ${ }^{1 *}$, Katharine Bowker ${ }^{1}$, Sophie Orton ${ }^{1}$, Felix Naughton², Sue Cooper ${ }^{1}$, Tim Coleman ${ }^{1}$ \\ From 3rd International Clinical Trials Methodology Conference \\ Glasgow, UK. 16-17 November 2015
}

\section{Background}

Smoking during pregnancy increases the risks of many pregnancy-related complications. MiQuit is a tailored, self-help, text-message intervention developed to help pregnant smokers to stop. A pilot RCT investigated feasibility of recruitment of women attending hospital antenatal clinics by using NIHR Clinical Research Network (CRN) research midwives (RMs); findings will be used to plan a future definitive trial to investigate MiQuit efficacy. We aimed to describe the facilitators and barriers to trial recruitment that RMs perceived, and relate these to key recruitment processes.

\section{Methods}

We conducted 14 semi-structured telephone interviews with RMs from 13 of 15 pilot trial recruiting centres. All interviewees had been involved in local study set-up, participant recruitment and follow-up. Data were transcribed verbatim, transcripts were coded simultaneously and inductive thematic analysis was used to analyse data.

\section{Conclusions}

Qualitative exploration of research staff views can help maximise the value of pilot work, identifying key aspects of trial design and conduct that may affect recruitment. We will discuss how these findings can assist planning a definitive trial, highlighting issues which may be generalisable to other studies.

\section{Authors' details}

${ }^{1}$ University of Nottingham, Nottingham, UK. ${ }^{2}$ University of Cambridge, Cambridge, UK.

Published: 16 November 2015

doi:10.1186/1745-6215-16-S2-P74

Cite this article as: Foster et al: Using qualitative interviews with nihr crn research midwives to refine trial recruitment methods. Trials 2015 16(Suppl 2):P74.

\section{Results}

Emergent findings suggest a number of pertinent themes, most notably with participant identification and screening. For example, experienced RMs generally felt that a screening questionnaire intended to be given to all women attending antenatal clinics, and therefore prevent smokers from feeling unfairly targeted, was ineffective when used in the proposed manner and could cause greater discomfort on both sides. Instead, RMs indicated that they preferred to pre-identify smokers and discreetly approach them.

${ }^{1}$ University of Nottingham, Nottingham, UK

Full list of author information is available at the end of the article

Submit your next manuscript to BioMed Central and take full advantage of:

- Convenient online submission

- Thorough peer review

- No space constraints or color figure charges

- Immediate publication on acceptance

- Inclusion in PubMed, CAS, Scopus and Google Scholar

- Research which is freely available for redistribution
() Biomed Central 